\title{
Una Iglesia pobre para los pobres ¿Adónde nos lleva el sueño del papa Francisco?*
}

\section{Pedro Trigo, Centro Gumilla, Caracas}

El nuevo obispo de Roma, Francisco, sorpresivamente para la mayoría, recogió en su primera comparecencia ante la prensa internacional el gran anhelo del inspirador del concilio, Juan XXIII, que quería una Iglesia de todos y principalmente una Iglesia de los pobres. Decía el papa, en un mensaje difundido por la radio vaticana el 11 de septiembre de 1962, un mes antes del inicio del concilio: "De cara a los países pobres, la Iglesia se presenta como es y quiere ser: la Iglesia de todos, pero especialmente la Iglesia de los pobres". Recogiendo esta misma inspiración o coincidiendo con ella, si es que no recordaba la cita de Juan XXIII y se limitó a manifestar su propio anhelo, el papa Francisco dijo a los periodistas: "¡Cómo me gustaría una Iglesia pobre, para los pobres!”.

Juan XXIII se había referido a la Iglesia como una Iglesia de todos, pero especialmente de los pobres, y Francisco añadió que esa Iglesia de los pobres tenía que ser una Iglesia pobre. Este anhelo de ambos, que no puede ser interpretado como un simple desahogo momentáneo sin mayor trascendencia, sino que debe entenderse como un designio, como una dirección vital y como un programa, puede ser interpretado de diversas formas. Vamos a especificarlas, pues la trascendencia de este programa depende del sentido que dieron a estas palabras.

* Ponencia del 7 de septiembre del 2013, pronunciada en la capilla del Centro Monseñor Romero de San Salvador. Mantenemos el tono oral del texto sin notas bibliográficas. 


\section{Qué no significa y qué significa una Iglesia pobre de los pobres}

Entendiéndolos de menos a más, encontramos tres sentidos en esta expresión: ante todo, el sentido restringido de que todos y especialmente los pobres son destinatarios de la acción de la Iglesia, que se distinguiría de ellos como la institución de salvación que los tiene a ellos como sus destinatarios principales. En segundo lugar, la expresión puede ser entendida como el anhelo de una Iglesia en la que todos se sientan en su casa, especialmente los pobres, en el sentido de un ámbito abierto, que todos y especialmente los pobres puedan hacer suyo. Y finalmente, puede entenderse también como una Iglesia en la que todos sean sujetos, especialmente los pobres.

\subsection{Una Iglesia de no pobres para los pobres}

La primera acepción es la que ha prevalecido durante el tiempo muy prolongado de la cristiandad, al que, al menos programáticamente, puso fin el concilio. La expresión más elocuente de esa manera de entender la relación de la Iglesia con la humanidad y en ella con los pobres, se encuentra en el esquema que había preparado la curia sobre la Iglesia, que la identificaba con la institución eclesiástica, es decir, con la jerarquía, que regía, santificaba y enseñaba a los fieles cristianos. La expresión "ir a la iglesia" lo expresaba con claridad, ya que no significaba solo ir al templo, sino a encontrarse con Dios en ese ámbito de sacralidad que administraban los clérigos. En ese mismo sentido decía el mandamiento de la santa madre Iglesia: "Oír misa entera todos los domingos y fiestas de guardar". El entendido era que la misa la dicen los sacerdotes y la oyen los laicos, que no son Iglesia, sino que van a la Iglesia, la de los sacerdotes. En ese mismo sentido dijo Pío X que el único derecho que tienen los laicos en la Iglesia es el de ser regidos por sus pastores.

Para que se vea la dificultad de superar este modo de entender la Iglesia, tenemos que recordar que este sentido se empezó a forjar antes de Constantino, en el siglo III, cuando los presbíteros y los obispos se fueron asimilando a los órdenes en los que se encuadraban en el Imperio romano las clases rectoras, fundamentalmente, al orden de los caballeros, los presbíteros, y al de los senadores, los obispos. En cuanto se aceptó esta figura, quedaba seriamente relativizado y casi negado el estatuto de hermanos en Cristo que distinguía a todos los cristianos. Desde Constantino y más todavía desde Teodosio, este estatuto diferenciador quedaba convalidado legalmente. Con este paso, aun a nivel civil, la Iglesia se asimilaba a la institución eclesiástica.

Esto se hizo mucho más macizo al aceptar la Iglesia la propuesta imperial de que la Cena del Señor se transformara en el sacrificio legítimo ofrecido a la divinidad "urbi et orbi", por la ciudad y el mundo, que equivalía a of recerse por el imperio y por su capital. Esto es así porque quien ofrecía el sacrificio era el 
sacerdote y lo ofrecía en favor de los asistentes y especialmente de los oferentes, uno de los cuales era siempre precisamente el Imperio romano. Ahí está el fundamento de la expresión "oír misa".

Sin embargo, en este esquema dicotómico, no se puede dudar, no fueron olvidados los pobres. Por el contrario, siempre, en unos tiempos y lugares más que en otros, hubo muchas iniciativas para atenderlos. Con mucha frecuencia, la Iglesia era su paño de lágrimas, casi la única institución que los amparaba y a veces con gran eficacia e incluso ternura.

La máxima expresión de las posibilidades de este esquema se plasmó en un auto sacramental del siglo de oro español: El gran teatro del mundo, de Calderón de la Barca. En este escenario mundial, Dios da a cada ser humano un papel, y el juicio de cada persona se hace únicamente en base a su desempeño. Desde esta perspectiva, realmente tradicional en la Iglesia, es decir, parte integrante de la Tradición (con mayúscula) que se remonta hasta Jesucristo, a pesar de que en la práctica haya sido relegada con frecuencia, los papeles son solo papeles: ellos no definen el estatuto humano. Como se ve, este planteamiento relativiza radicalmente la organización piramidal de la sociedad. Esas diferencias de rangos no tienen ninguna trascendencia. Por tanto, definirse por ellas es vanidad y locura o, para decirlo en términos bíblicos, necedad, es decir, extravío total. Ante Dios, que es el que tiene la última palabra que dice la verdad de todo, solo cuenta el desempeño de cada actor. Y concretamente en esa obra de teatro, el que lo hace mejor es el mendigo. Él queda por delante del rey. Así, pues, todos tenemos posibilidad de ser los más humanos ante la estimativa de Dios, que desentraña lo que hay realmente en los corazones. Y es muy significativo de la densidad cristiana de la obra, que por eso es auto sacramental en el sentido más denso de la palabra, que el más humano de esa situación histórica sea el pobre.

Esto es radicalmente cristiano, pero el límite es que los papeles están prefijados. De este modo se naturalizan los roles sociales; aunque no se sacralizan, porque todos en definitiva tienen que responder de su desempeño ante Dios. Es decir, que puesto que los papeles están prefijados, los pobres siempre tienen que ser socorridos, no pueden salir de su pobreza. Aunque, en medio de ella, puedan vivir humanamente, incluso de un modo eximiamente humano.

Esto lo han sabido muchos pobres a lo largo de la historia cristiana y, en consecuencia, han vivido con dignidad. Ahora bien, ellos podían ser buenos cristianos, e incluso santos, pero respecto de la Iglesia, es decir, de la institución eclesiástica, eran únicamente destinatarios.

Pues bien, tenemos que decir que este sentido fue desechado por el concilio al señalar como sujeto de la Iglesia a todo el pueblo de Dios, en su condición primordial y definitiva de cristianos, es decir, de hijos de Dios, en su Hijo único Jesús, y de hermanos de todos, en el Hermano universal, desde el privilegio de 
los pobres. Las diversas vocaciones (jerarquía, vida consagrada y laicado) vienen después y están íntegramente ordenadas a ayudarnos mutuamente a vivir como cristianos y a expandir por el mundo la fraternidad de hijas e hijos de Dios.

Así, pues, una Iglesia de los pobres o para los pobres no es una Iglesia, identificada con la institución eclesiástica, que atiende solícitamente a los pobres, que son los destinatarios de su acción. Y, sin embargo, hay que decir que eso sigue siendo la Iglesia muchas veces, en el mejor de los casos, es decir, cuando de hecho los atiende. En el individualismo reinante con la inclinación casi irresistible al lucro y al consumismo y la lucha tan despiadada por competir, dar algo a los pobres o hacer algo por ellos es una actitud que debe ser positivamente valorada y fomentada. Hay que sostener, sin embargo, que, en el sentido fuerte de la palabra, no es cristiana una institución que es para los pobres, pero no con los pobres ni, en algún sentido al menos, de ellos.

\subsection{La Iglesia como un ámbito que los pobres sienten suyo}

La segunda acepción es la de la Iglesia como un ámbito en el que todos y, sobre todo, los pobres puedan sentirse en casa. Para decirlo gráficamente, la Iglesia es la casa de Dios, que por eso es la casa de todos y, sobre todo, la casa del pueblo, de los pobres. Como se ve, la Iglesia es un ámbito distinto que el ámbito institución. Aquí, ámbito se concretaría como ámbito de salvación, que no equivale a ámbito sagrado en contraposición a profano, sino a una asequibilidad del Dios de la salvación y de la salvación de Dios, abierto y disponible para los creyentes, que tiene signos y símbolos, pero que no se restringe a ellos.

El concilio reconoció esta acepción porque entendió a la Iglesia no como la institución de salvación, fuera de la cual no la hay, sino como un sacramento de salvación universal y de la unión de todo el género humano $(L G 1,1 ; 2,9)$, y, consiguientemente, consideró que de algún modo, todos pertenecían o se ordenaban a ella y, en ese sentido, que en ella cabían todos $(L G 2,13-16)$. Por una parte, consideró que la gracia del Crucificado resucitado actúa victoriosamente sobre toda carne, por el Espíritu derramado en la Pascua. Por tanto, no tiene ya lugar esa dualidad estructural entre salvadores y salvados. Todos, desde el papa para abajo, somos ante todo salvados, todos necesitamos siempre ser salvados; pero también todos podemos obrar la salvación porque el Espíritu del Hijo actúa en cada corazón humano y en el corazón de la historia. De eso es sacramento la Iglesia. Es decir, a la Iglesia se le ha revelado este acontecimiento, esta presencia de la definitividad en todos los seres humanos, para que la proclame como buena nueva, entregando, sobre todo, los santos Evangelios, y para que la haga presente con su vida comunitaria y con la actuación ciudadana de sus miembros. Por esta presencia del Espíritu en todos, todos caben de un modo u otro en ella. Y, sobre todo, los pobres, que llevan la imagen de su fundador. 
Hay que decir que esta acepción ha estado operante a lo largo de toda la historia de la Iglesia. Aunque la institución eclesiástica se haya sentido casi dueña de ese ámbito, el pueblo pobre siempre ha sabido que en la Iglesia tiene acceso expedito a Dios y se ha sentido en libertad en ella; se ha sentido realmente en su casa, a veces con la anuencia de la institución eclesiástica y a veces a pesar de su reticencia. Los pobres no se han ido de la Iglesia, a pesar de que frecuentemente no hayan sido bien recibidos. A ellos les duele, sin duda, pero no se van porque en el fondo saben que tienen derecho de estar en ella.

En esta acepción, lo que le toca a la institución eclesiástica es reconocer ese derecho del pueblo que, como decía el Antiguo Catecismo Astete que estudiamos de niños, no es cristiano por la benevolencia del cura, sino por la gracia de Dios. La expresión más radical de este reconocimiento es la comunión de la institución eclesiástica con el pueblo cristiano pobre. La primera comunión es la comunión de todos los cristianos como cristianos: la vivencia de la fraternidad de las hijas e hijos de Dios. La segunda comunión, encaminada toda ella, como dijimos, a cualificar la primera, tiene dos expresiones: la primera, esta que acabamos de mencionar: la comunión de la institución eclesiástica con el pueblo cristiano, en cuyo seno se encuentra ella; comunión, sobre todo, con los pobres. La segunda expresión es la comunión del pueblo de Dios con la institución eclesiástica. Esta forma de comunión, desgraciadamente, suele ser la única que se nombra, pero hay que resaltar que no es fecunda, si no va montada sobre las dos formas precedentes de comunión. Y que es fecundísima, como lo fue la Iglesia de Medellín y Puebla, si viene después de ellas. Comulgar con los pobres es reconocerles que están en la Iglesia por derecho propio, por derecho evangélico. Que ese ámbito es suyo y que la institución eclesiástica está para servirlos. Hay minorías que así lo sienten y viven, pero, desgraciadamente, esta actitud no es la que da el tono a la institución. En este punto hay una llamada muy seria a la conversión institucional.

\subsection{Una Iglesia en la que los pobres son sujetos privilegiados, que opta por ellos}

La tercera acepción es la que propone el concilio como novedad histórica, aunque absolutamente enraizada en los santos Evangelios: una Iglesia en la que los pobres sean sujetos, más aún, en la que los pobres con espíritu sean reconocidos como su jerarquía espiritual, como el corazón de la Iglesia. Ante todo, el concilio reconoció que la Iglesia somos todos los bautizados, en cuanto cristianos $(L G 2,9)$, y no solo la institución eclesiástica, que, como tal, es una mera función, dentro del pueblo de Dios. Pero, sobre todo, dentro de este pueblo santo de Dios, el concilio reconoció en los pobres, "la imagen de su fundador pobre" $(L G 1,8)$.

También el concilio se refirió a la Iglesia pobre: "Mas como Cristo efectuó la redención en la pobreza y en la persecución, así la Iglesia es llamada a seguir ese mismo camino para comunicar a los seres humanos los frutos de la salvación" $(L G 1,8)$. 
Si el concilio se refirió parcamente a la Iglesia pobre de los pobres, muchísimo más hicieron suya esta expresión en el sentido más fuerte las Conferencias Generales del Episcopado Latinoamericano de Medellín y Puebla, que lo recibieron creativamente para América Latina. Medellín dedicó un capítulo entero (n. $\left.{ }^{\circ} 14\right)$ a indicaciones concretas para que nuestra Iglesia llegue a ser una Iglesia pobre, y Puebla consideró sujetos a los pobres hasta el punto de declarar que su modo de vivir el cristianismo "es una fuerza activa con la que el pueblo se evangeliza constantemente a sí mismo".

Como se ve, este anhelo del corazón del papa Francisco está enraizado en lo más genuino del concilio y de su recepción latinoamericana, viene, pues, sin duda, del Espíritu y, por eso, todo lo que conduzca a ponerlo en práctica es de Dios.

\section{2. ¿Es nuestra Iglesia una Iglesia pobre de los pobres?}

En esta segunda parte no me voy a referir a la Iglesia universal ni al Vaticano. Tenemos el peligro de caer en tópicos descomprometidos. Me parece más fecundo preguntarnos por nuestra Iglesia concreta, aquella de la que formamos parte y en la que tenemos, por tanto, una responsabilidad dada por nuestro Dios al llamarnos a ella. Yo me referiré a mi Iglesia venezolana para que ustedes vayan pensando al mismo tiempo en la suya salvadoreña.

Lo primero que podemos hacer como católicos es un examen de conciencia sobre dónde estamos como Iglesia respecto a este anhelo de los papas Juan y Francisco y, en el fondo, de nuestro Señor Jesucristo, para caminar desde donde estamos hacia donde nos llama Dios.

\subsection{Sí lo es, pero no lo reconoce}

Creo que, en gran medida, la respuesta a si somos una Iglesia pobre y de los pobres es afirmativa, ya que la mayoría del pueblo de Dios (que eso es la Iglesia) es gente pobre abierta a los pobres. Si mantenemos la perspectiva del Concilio Vaticano II, para el que la Iglesia somos todos los cristianos, esta afirmación básica no puede quedar desmentida entre nosotros porque la mayoría de los católicos venezolanos son pobres. En este sentido, también tenemos que afirmar que, de hecho, los pobres con espíritu constituyen el corazón de nuestra Iglesia, ya que ellos forman su verdadera jerarquía espiritual (que no tienen ningún deseo de sustituir a la ministerial), y ellos son principalmente quienes transmiten la fe como una llama prende a otra llama, y quienes evangelizan con su vida y dando razón de su esperanza. Podemos calificar lo que acabamos de decir como el hecho mayor de nuestra Iglesia. Y es la fuente de nuestra esperanza.

Ahora bien, una cosa es que, de hecho, nuestra Iglesia sea en gran medida una Iglesia de los pobres y para los pobres, y otra, bien distinta, que tenga conciencia de ello. Si preguntamos por la conciencia, hay que responder que no tenemos 
conciencia de que sea así. Los pobres con espíritu se sienten en la Iglesia, ella es su casa y se relacionan con los otros como hermanos en la fe; pero lo viven como algo que sucede por la misericordia de Dios que los ha llamado y no se preguntan por su lugar en la Iglesia ni por su ser Iglesia. Les basta con saberse dentro, acogidos por Dios y animados por su Espíritu, y aceptan la mediación de los ministros con naturalidad, ya que, obviamente, ninguno de ellos es presbítero ni obispo.

Por eso, para quienes siguen identificando a la Iglesia con la institución eclesiástica, que son la mayoría, tanto de los que se consideran en la Iglesia como de los que son cristianos sin afiliación, como de los que no son católicos o cristianos, no tiene sentido lo que estamos diciendo. Según la opinión establecida, que sigue dando la pauta, la Iglesia es la institución eclesiástica. Así lo cree en la práctica la casi totalidad de ella, aunque una parte, incluidos la mayoría de los obispos, confiesen, cuando se les hace la pregunta explícita, que la Iglesia somos todos, todo el pueblo de Dios, en el que están en lugar destacado los pobres. Pero una cosa es lo que se profesa y otra lo que se vive en la cotidianidad y cuando se tienen que tomar decisiones.

Pues bien, para ese sentir obvio que identifica Iglesia e institución eclesiástica, la Iglesia venezolana no es una Iglesia pobre ni de los pobres. Sin embargo, lo matizaría porque, si bien es verdad que los obispos y los curas no son (somos) pobres, también lo es que la inmensa mayoría tampoco son ricos ni de clase media alta o media, sino de clase media baja o de clase popular, y para bastantes de ellos su referencia primordial es también gente de clase popular o media baja, y además un grupo minoritario optan decididamente por los pobres, y, en ese sentido, forman parte de la Iglesia de los pobres no solo porque vivan principalmente para ellos, sino también porque consideran lo que dijimos al principio: que los pobres forman en la realidad el corazón de la Iglesia y son los que más viven y comunican la fe y, en particular, los que alimentan la de ellos, que son sus pastores fraternos. No es una fe ideológica, doctrinal, sino la fe que salva: la entrega confiada en las manos de Dios, en el Dios de Jesús para que dirija sus vidas.

Así, pues, se da la paradoja de que es precisamente una parte minoritaria, pero significativa, de la institución eclesiástica la que sostiene la afirmación primera de que la mayoría, lo más vivo de la Iglesia venezolana, sí es pobre y vive abierta a los pobres. Tal vez ellos son en el país los únicos que sostienen esa tesis y son capaces de argumentarla y, sobre todo, la experimentan gozosamente.

\subsection{Los responsables y los que dan el tono no van en esa dirección}

Ahora bien, dicho esto, sí habría que insistir, complementariamente, en que la inmensa mayoría de la institución eclesiástica y del resto del pueblo de Dios no pobre está muy lejos de sacar consecuencias de ese hecho mayor. Una parte considerable simplemente no lo reconoce y quienes sí lo hacen no lo reconocen como algo que los ataña y, menos aún, como una buena nueva para ellos. Y por 
eso, no se reconoce la excelencia cristiana de los pobres ni se les acompaña o apoya, ni, muchísimo menos, se ponen en su discipulado.

Incluso esto último parece, para la mayoría de los cristianos, una afirmación sin sentido porque piensan que esos pobres saben menos que ellos de cristianismo y no tienen nada que enseñarles. Desgraciadamente están presos del conocimiento objetual y no captan el sentido del conocimiento bíblico que es el que se da a través de la relación íntima (Gn 2, 9; 3, 5; 41). Por eso, el que ama conoce a Dios y el que no ama no conoce a Dios, porque Dios es Amor (1 Jn 4, 7-8). Así hablaba ya Jeremías de Josías: "Hizo justicia a los pobres y desvalidos. ¿Acaso no es eso conocerme?" $(22,16)$.

Así, pues, hay que decir que la dirección de los responsables de nuestra Iglesia y de los que llevan la voz cantante y configuran la opinión no va hacia la constitución de una Iglesia pobre ni para los pobres. Y no es porque se prescinda de ellos ni se les desprecie. Todos los responsables admiten que ellos son la mayoría de los católicos y se les acoge y hasta se les mira con una cierta simpatía. En ese sentido, afirmamos que no somos de ningún modo una Iglesia clasista ni elitista. Por eso los pobres se sienten en ella, si no a gusto ni reconocidos, sí en su casa, con naturalidad. Pero, reconocido esto, también es verdad que ese sesgo doctrinario, que desgraciadamente ha acompañado a la Iglesia latinoamericana desde su nacimiento, ha tenido como consecuencia que se les vea como menores de edad y que no se reconozca su jerarquía espiritual ni se vaya en camino de reconocerlo.

\subsection{Se caminó hacia una Iglesia de los pobres, pero en gran medida se ha abandonado esa dirección}

Todavía tendríamos que afirmar algo más grave: la Iglesia venezolana, y más señaladamente la vida religiosa en ella, se puso en camino de este reconocimiento. El hecho mayor de nuestra Iglesia, tal vez en toda su historia, fue la inserción inculturada de muchos agentes pastorales en el medio popular, sobre todo suburbano, donde trataron a los pobladores como vecinos, en relaciones horizontales y mutuas, donde acompañaron y se sintieron acompañados, donde transmitieron lo mejor que tenían y recibieron el tesoro invalorable de experimentar la densidad humana de muchas personas del pueblo, de apoyarse en su fe y de recibir agradecidos los dones de su generosidad. Este encuentro despertó una gran esperanza, dinamizó a estas personas y dio lugar a multitud de grupos y comunidades.

Pero la crisis económica y de personal, unida al cambio de época, llevó a un enfoque reinstitucionalizador que provocó un progresivo abandono de estas comunidades insertas para concentrarse en grandes instituciones. Ahora el tono lo da el pietismo, el predominio de lo devocional, separado de la vida y no alimentado por la lectura orante del Evangelio, al contrario de lo que dio el tono 
a ese encuentro fecundo. El segmento más modernizado apuesta, como era de esperar, por el corporativismo: familias, supuestamente carismáticas, que giran alrededor de señas de identidad más que de actuaciones carismáticas, que son siempre abiertas.

\section{4. ¿Nos decidiremos a caminar en esa dirección?}

El Concilio Plenario Venezolano recogió, sistematizó y relanzó con un gran sentido de oportunidad lo mejor de la época pasada. Él sí concibió muy concretamente una Iglesia pobre y para los pobres; pero, por ahora, no tiene sujeto que se responsabilice de él y lo lleve a la práctica.

Dios quiera que estemos equivocados y que, aunque oculto a nuestros ojos, esté surgiendo ese sujeto. Nunca hemos querido más equivocarnos que al escribir esta nota. Y Dios quiera que la frase inicial del nuevo obispo de Roma a la prensa internacional, que ha servido de horizonte para este examen de conciencia, nos aleccione para enrumbarnos, y que sus gestos y sus decisiones nos animen e incluso nos empujen hacia ellos.

\section{3. ¿Con cuánto anhelo quiere Francisco realizar ese anhelo?}

\subsection{Una anécdota personal}

Para calibrar ese empeño, permítanme comenzar por una anécdota personal, que no se refiere al papa Francisco y ni siquiera al arzobispo de Buenos Aires, sino a un compañero jesuita, llamado Jorge Bergoglio, que se desempeñaba entonces como rector del Colegio Máximo del Salvador, sede de las facultades de Filosofía y Teología y residencia de los escolares jesuitas en el gran Buenos Aires.

He contado muchas veces esta anécdota para mostrar lo que Bergoglio entendía por alienación: una energía genuina, pero extraviada. Si se subsana el extravío, la energía puede dar todo de sí. El Colegio Máximo era aquel año, me refiero a 1986, la sede del encuentro anual de un grupo de jesuitas, profesores de filosofía de los distintos países de América Latina. En los siete días que estuvimos allí no comimos carne ni pescado ni un solo día. Era la opción del rector, una opción que en Argentina equivalía a pobreza extrema. Además, todos los estudiantes hacían su apostolado en barrios. No se podía dudar de que había una opción maciza por vivir pobremente y darse a los pobres.

Hasta aquí, la energía genuina. Pero los muchachos iban a los barrios vestidos de clérigos y para funciones estrictamente religiosas, como si se restringieran a un ámbito de la realidad separado del resto. Además, nos escandalizaba que no pocos exculpaban a los militares.

El rector me insistió que tenía mucho interés en hablar conmigo. El tema era la teología de la liberación. El tono fue muy amable, y me preguntaba y 
volvía a preguntar insistentemente. Yo interpreté que tenía un bloqueo sobre esta corriente eclesial y que me preguntaba a mí porque intuía que yo tendría posiciones, digámoslo así, más blandas que Ellacuría, el otro compañero del grupo de visitantes que iba en esa dirección.

Cuando regresé de nuevo y él era ya obispo de Buenos Aires, tuve interés en indagar sobre su línea y me respondieron lo que es de todos conocido: su sencillez, muy excepcional, de vida, desde el apartamento en que vivía a la costumbre de viajar en autobús y en metro, a la atención a los pobres concretos y el servicio muy horizontal a los curas. Concluí que, superado ese impasse, la energía, que era del todo genuina, estaba dando de sí sin ningún impedimento.

$\mathrm{Si}$ esta anécdota no hace inferencias indebidas, hay que concluir que la convicción de que hay que ser pobre y tener una cercanía real, humana, horizontal con los pobres, es para él un elemento central de su ser cristiano y de su modo de concebir el cristianismo y, por ende, la Iglesia. Creo que en lo que va de pontificado, ha dado muestras de que es así en verdad.

Una confirmación de que la interferencia es lo que él entendía como ideologización indebida está en lo que dijo en Río a los representantes del Celam como una de las tentaciones que acechan al discípulo misionero: "El reduccionismo socializante es la ideologización más fácil de descubrir. En algunos momentos fue muy fuerte. Se trata de una pretensión interpretativa en base a una hermenéutica según las ciencias sociales. Abarca los campos más variados, desde el liberalismo de mercado hasta la categorización marxista". Como se ve, para él es fundamentalmente cosa del pasado, aunque sigue como tentación de la que hay que precaverse.

\subsection{Punto de partida insólito: no dar por supuesto qué es ser papa}

Me voy a referir, a continuación, a un punto que a mi modo de ver está a la base de todos sus gestos, tan significativos y que están sembrando por doquier tanta esperanza. Lo que hace posible todo lo que asombra es que, al contrario de sus antecesores, Francisco no dio por supuesto lo que implicaba ser papa. La costumbre era que el entorno iba indicando al elegido en cada caso qué era lo que se hacía. Como acababa de ser elegido, iba siguiendo las pautas de los que se suponía que sabían, y cuando se quería dar cuenta, ya se había amoldado a lo consabido. Si no sucedía que él también pertenecía al aparato y lo tenía ya interiorizado. En este esquema lo más que cabía eran variaciones sobre lo mismo.

Pues bien, la sabiduría del papa Francisco lo guio a no dar nada por supuesto, y así desde el inicio fue haciendo lo que le salía de dentro, no lo que se suponía que tenía que hacer. Desde comenzar pidiendo la bendición y que oraran por él en vez de comenzar impartiendo la bendición, hasta no irse a vivir a las habitaciones papales, sino permanecer en la residencia de los huéspedes, hasta, más 
aún, consultar a los que él quiere y no a los que se supone debe consultar antes de tomar decisiones. Así dejó de ser rehén de la curia.

\subsection{Cuatro gestos como muestra}

Que este modo de proceder no sea mera astucia humana, sino un impulso realmente trascendente lo revelan los gestos que están reseñados en la invitación a esta convocatoria del Jueves Santo: ha lavado los pies a una docena de jóvenes en una prisión de Roma, entre ellos una musulmana serbia.

En la presentación de las cartas credenciales de cuatro embajadores ante la Santa Sede, ha denunciado el totalitarismo del capital como una idolatría fetichista:

Hay que reconocer que la mayoría de los hombres y de las mujeres de nuestro tiempo siguen viviendo en precariedad cotidiana, con consecuencias funestas. Algunas patologías aumentan, con sus consecuencias psicológicas, el miedo y la desesperación se apoderan de los corazones de numerosas personas, incluso en los llamados países ricos; la alegría de vivir va disminuyendo; la indecencia y la violencia aumentan; la pobreza se vuelve cada vez más impactante. Se tiene que luchar para vivir, y, a menudo, para vivir sin dignidad. Una de las causas de esta situación, en mi opinión, se encuentra en nuestra relación con el dinero y en nuestra aceptación de su imperio y dominio en nuestro ser y en nuestras sociedades. De este modo, la crisis financiera que estamos viviendo nos hace olvidar que su primer origen se encuentra en una profunda crisis antropológica, ¡en la negación de la primacía del hombre! Hemos creado nuevos ídolos. La adoración del antiguo becerro de oro ( $c f$. Ex 32, 15-34) ha encontrado una imagen nueva y despiadada en el fetichismo del dinero y en la dictadura de la economía sin rostro y sin un objetivo verdaderamente humano.

$\mathrm{Su}$ primer viaje oficial lo ha hecho a la isla Lampedusa, lugar de tragedia y muerte para miles de africanos que tratan de llegar a Europa, y precisamente después de que los tripulantes de un pesquero rompieran las redes a las que se agarraban africanos náufragos como su única tabla de salvación, provocando que se ahogaran todos, y como una respuesta a este asesinato a sangre fría que revela la inhumanidad de los propietarios, un ejemplo espeluznante de lo que acababa de denunciar. Por eso, en Lampedusa ha denunciado "la tiranía del dinero" y la "globalización de la indiferencia ante el drama de los indocumentados".

Ha visitado la favela de Varginha en Río de Janeiro para denunciar la apatía ante la desigualdad escandalosa.

En estos cuatro ejemplos, puede dibujarse su hacerse presente en el mundo de los pobres para dar esperanza con su presencia personalizada y ofrecer el diseño del horizonte estructural en el que acontecen estos actos fraternos de misericordia, que es la denuncia de frente y a fondo de la inhumanidad del sistema, que 
no solo es idolátrico, ya que sustituye a Dios por el dios dinero, sino que no duda en sacrificar a millones de personas para alimentar a ese ídolo insaciable.

\subsection{Alocuciones en la Jornada Mundial de la Juventud}

Para que se palpe que estos ejemplos son realmente representativos, vamos a referirnos a las diversas alocuciones que tuvo durante su permanencia en Brasil en la Jornada Mundial de la Juventud.

Ante todo quiero destacar, porque me parece particularmente significativo, cómo se presenta ante los que habla. Comencemos por el discurso de respuesta a la bienvenida de las autoridades. Él no se presenta como un jefe de Estado ni como alguien que, por lo que representa, se coloca por encima. Se presenta, por el contrario, como alguien que entra pidiendo permiso, como la gente popular, y que apela, por eso, a la benevolencia de sus huéspedes:

He aprendido que, para tener acceso al pueblo brasileño, hay que entrar por el portal de su inmenso corazón; permítanme, pues, que llame suavemente a esa puerta. Pido permiso para entrar y pasar esta semana con ustedes. No tengo oro ni plata, pero traigo conmigo lo más valioso que se me ha dado: Jesucristo. Vengo en su nombre para alimentar la llama de amor fraterno que arde en todo corazón; y deseo que llegue a todos y a cada uno mi saludo: la paz de Cristo esté con ustedes.

Al final del discurso retoma la misma idea: "Ruego a todos la gentileza de la atención y, si es posible, la empatía necesaria para establecer un diálogo entre amigos".

Quien habla así no se siente representante del Dios de los dioses y Señor de los señores, sino del Mesías pobre de los pobres.

Esta conciencia de fraternidad estructural y, por eso, de relaciones horizontales y mutuas, se echa de ver desde el comienzo en el saludo a los jóvenes venidos a la jornada: "Hoy he venido a confirmarles en esta fe, la fe en Cristo vivo que habita en ustedes, pero he venido también para ser confirmado por el entusiasmo de su fe". Su papel de obispo de Roma es confirmar a sus hermanos en la fe, pero como antes que obispo es hermano en Cristo, también está consciente de que necesita ser confirmado por la fe de los jóvenes y también viene a eso.

Por eso insiste a los obispos que ese talante es el que tiene que distinguir a la Iglesia, si quiere dar fruto:

La barca de la Iglesia no tiene la potencia de los grandes transatlánticos que surcan los océanos. Y, sin embargo, Dios quiere manifestarse precisamente a través de nuestros medios, medios pobres, porque es siempre él quien actúa. Queridos hermanos: el resultado del trabajo pastoral no se basa en la riqueza de los recursos, sino en la creatividad del amor. 
Es lo mismo que dice a los representantes del Celam: "Por favor, les pido que tomemos en serio nuestra vocación de servidores del santo pueblo fiel de Dios, porque en esto se ejercita y se muestra la autoridad: en la capacidad de servicio".

Ahora bien, el servicio no es solo una actitud interna, también demanda un lugar social. El obispo no puede aparecer ante los demás como un príncipe de la Iglesia, sino como un pobre de su sociedad: "Hombres que amen la pobreza, sea la pobreza interior como libertad ante el Señor, sea la pobreza exterior como simplicidad y austeridad de vida. Hombres que no tengan "psicología de príncipes"”.

Esto exige que los obispos, los sacerdotes, las religiosas y los seminaristas vayan a contracorriente del humanismo economicista que se ha impuesto y que practiquen denodadamente la solidaridad fraterna. Así lo expresa en el discurso dirigido a ellos:

En este humanismo economicista que se nos impuso en el mundo, se ha abierto paso una cultura de la exclusión, una "cultura del descarte". No hay lugar para el anciano ni para el hijo no deseado; no hay tiempo para detenerse con aquel pobre en la calle. A veces parece que, para algunos, las relaciones humanas están reguladas por dos "dogmas": eficiencia y pragmatismo. Queridos obispos, sacerdotes, religiosos, religiosas y ustedes seminaristas que se preparan para el ministerio: tengan el valor de ir contracorriente de esta cultura (...) eficientista, de esta cultura del descarte. El encuentro y la acogida de todos, la solidaridad, que es una palabra que están escondiendo en esta cultura, casi una mala palabra; la solidaridad y la fraternidad son los elementos que harán a nuestra civilización verdaderamente humana.

Si la institución eclesiástica va realmente a contracorriente de la dirección dominante de esta figura histórica, marcada por el culto al dinero y a la eficiencia economicista que lo persigue, podrá comenzar por atender lo elemental y lo básico sin dejarlo nunca de lado. Así lo insiste a los obispos: "La gente siempre necesita pan. Los hombres comienzan siempre por sus necesidades, también hoy".

Pero también tienen que comprender que los pobres no son solo los que necesitan. También son los que en su pobreza acogen a Dios, y en este punto hay que ponerse en su discipulado. Por eso, para que no se crean mayores que ellos ante Dios, les recuerda: "En la casa de los pobres, Dios siempre encuentra sitio".

A los dirigentes les propone tres cosas. La primera es rehabilitar la política y humanizar la economía. Esta labor es necesaria porque los gritos de los profetas, a causa de los agravios que los ricos hacen a los pobres y que los políticos dejan impunes, siguen teniendo actualidad:

El futuro exige hoy la tarea de rehabilitar la política, que es una de las formas más altas de la caridad. El futuro nos exige también una visión humanista de 
la economía y una política que logre cada vez más y mejor la participación de las personas, evite el elitismo y erradique la pobreza. Que a nadie le falte lo necesario y que se asegure a todos dignidad, fraternidad y solidaridad: este es el camino propuesto. Ya en la época del profeta Amós era muy frecuente la admonición de Dios: "Venden al justo por dinero, al pobre por un par de sandalias. Oprimen contra el polvo la cabeza de los míseros y tuercen el camino de los indigentes" (Am 2, 6-7). Los gritos que piden justicia continúan todavía hoy.

Como se echa de ver, la rehabilitación de la política y la transformación de la economía van encaminadas a hacer justicia a los pobres, esforzándose por erradicar la pobreza como una tarea central.

La segunda cosa que les pide es responsabilidad, en el sentido literal de la obligación de responder de sus actos ante Dios y ante los pueblos:

Quien actúa responsablemente pone la propia actividad ante los derechos de los demás y ante el juicio de Dios. Este sentido ético aparece hoy como un desafío histórico sin precedentes. Tenemos que buscarlo, tenemos que insertarlo en la misma sociedad. Además de la racionalidad científica y técnica, en la situación actual se impone la vinculación moral con una responsabilidad social y profundamente solidaria.

Lo tercero es diálogo en el sentido preciso de estar abiertos a la verdad y a los otros y de ser capaces de integrar todos los aportes, para lo que es indispensable ir más allá de la pretensión de salvaguardar los intereses establecidos:

Entre la indiferencia egoísta y la protesta violenta, siempre hay una opción posible: el diálogo. El diálogo entre las generaciones, el diálogo en el pueblo, porque todos somos pueblo, la capacidad de dar y recibir, permaneciendo abiertos a la verdad. Un país crece cuando sus diversas riquezas culturales dialogan de manera constructiva: la cultura popular, la universitaria, la juvenil, la artística, la tecnológica, la cultura económica, la cultura de la familia y de los medios de comunicación. ¡Cuánto diálogo hay! Es imposible imaginar un futuro para la sociedad sin una incisiva contribución de energías morales en una democracia que se quede encerrada en la pura lógica o en el mero equilibrio de la representación de los intereses establecidos (...) El único modo de que una persona, una familia, una sociedad, crezca; la única manera de que la vida de los pueblos avance, es la cultura del encuentro, una cultura en la que todo el mundo tiene algo bueno que aportar, y todos pueden recibir algo bueno a cambio. El otro siempre tiene algo que darme cuando sabemos acercarnos a él con actitud abierta y disponible, sin prejuicios. Esta actitud abierta, disponible y sin prejuicios yo la definiría como "humildad social", que es la que favorece el diálogo.

Lo que impide esa humildad social es estar determinado por los intereses creados, responder ante el poder del dinero y no ante los ciudadanos y en 
particular ante los pobres que claman no solo justicia, sino participación, ser tomados en cuenta.

En el vía crucis de la Jornada Mundial de la Juventud, hace ver a los jóvenes que Cristo carga la cruz con todos los crucificados de la historia y particularmente ayuda a los jóvenes a llevar las suyas:

Con la cruz, Jesús se une al silencio de las víctimas de la violencia, que ya no pueden gritar, sobre todo los inocentes y los indefensos (...) Con la cruz, Jesús se une a todas las personas que sufren hambre, en un mundo que, por otro lado, se permite el lujo de tirar cada día toneladas de alimentos. Con la cruz, Jesús está junto a tantas madres y padres que sufren al ver a sus hijos víctimas de paraísos artificiales, como la droga. Con la cruz, Jesús se une a quien es perseguido por su religión, por sus ideas, o simplemente por el color de su piel; en la cruz, Jesús está junto a tantos jóvenes que han perdido su confianza en las instituciones políticas porque ven el egoísmo y corrupción, o que han perdido su fe en la Iglesia, e incluso en Dios, por la incoherencia de los cristianos y de los ministros del Evangelio. Cuánto hacen sufrir a Jesús nuestras incoherencias. En la cruz de Cristo está el sufrimiento, el pecado del hombre, también el nuestro, y Él acoge todo con los brazos abiertos, carga sobre su espalda nuestras cruces y nos dice: ¡Ánimo! No la llevás vos solo. Yo la llevo contigo y yo he vencido a la muerte y he venido a darte esperanza, a darte vida.

No es solo que Cristo crucificado acompaña a quienes llevan la cruz, sino que, al abrazar nosotros a un pobre, se abraza la carne de Cristo. El papa no pudo ser más gráfico e incisivo; y no se limitó a decirlo, sino que abrazó a uno de los jóvenes que luchan por salir de la dependencia de la droga en el hospital de San Francisco: "En cada hermano y hermana en dificultad abrazamos la carne de Cristo que sufre. Hoy, en este lugar de lucha contra la dependencia química, quisiera abrazar a cada uno y a cada una de ustedes que son la carne de Cristo, y pedir que Dios colme de sentido y de firme esperanza su camino, y también el mío". Esta última petición es sintomática de una actitud primordial que estuvo presente desde que se asomó al balcón cuando lo eligieron papa: quien habla así no es alguien que se siente confirmado en gracia por ser representante de Jesucristo, sino un ser humano débil, necesitado, como el drogómano, de que Dios le dé esperanza.

Pero los jóvenes no son solo las víctimas del mundo que han hecho sus mayores. Ellos están llamados por el Señor a dejar a un lado el eficientismo consumista y la apatía que segrega. Por eso, el papa se anima a pedirles que ofrezcan respuestas a nivel social e incluso político. Es muy significativo que pida eso en una vigilia de oración: "Por ustedes entra el futuro en el mundo. A ustedes también les pido que sean protagonistas de este cambio. Sigan superando la apatía y ofreciendo una respuesta cristiana a las inquietudes sociales y políticas que se van planteando en diversas partes del mundo". 
Pero estos planteamientos estructurales tienen que ir acompañados de actitudes personales de raigambre evangélica para que las transformaciones sean de verdad humanizadoras. Así lo expresa en la misa de clausura: "Evangelizar es dar testimonio en primera persona del amor de Dios, es superar nuestros egoísmos, es servir inclinándose a lavar los pies de nuestros hermanos, como hizo Jesús".

Como en el caso de Jesús, la última imagen que queda es la del sirviente que lava los pies. Ese es, para el papa Francisco, el cristiano, esa es también la Iglesia que comenzó Jesucristo y la que nosotros tenemos que proseguir. Es bonito que nos lo recuerde el papa; pero somos nosotros quienes lo tenemos que llevar a cabo, y él también, como insiste una y otra vez. Que así sea. 